\title{
Signe de Thompson dans la rupture du tendon calcanéen
}

\section{Thompson's test for calcaneal tendon rupture}

\section{Giron · O. Peyrony $\cdot$ J.-P. Fontaine}

Reçu le 2 octobre 2031 ; accepté le 18 novembre 2013

(C) SFMU et Springer-Verlag France 2013

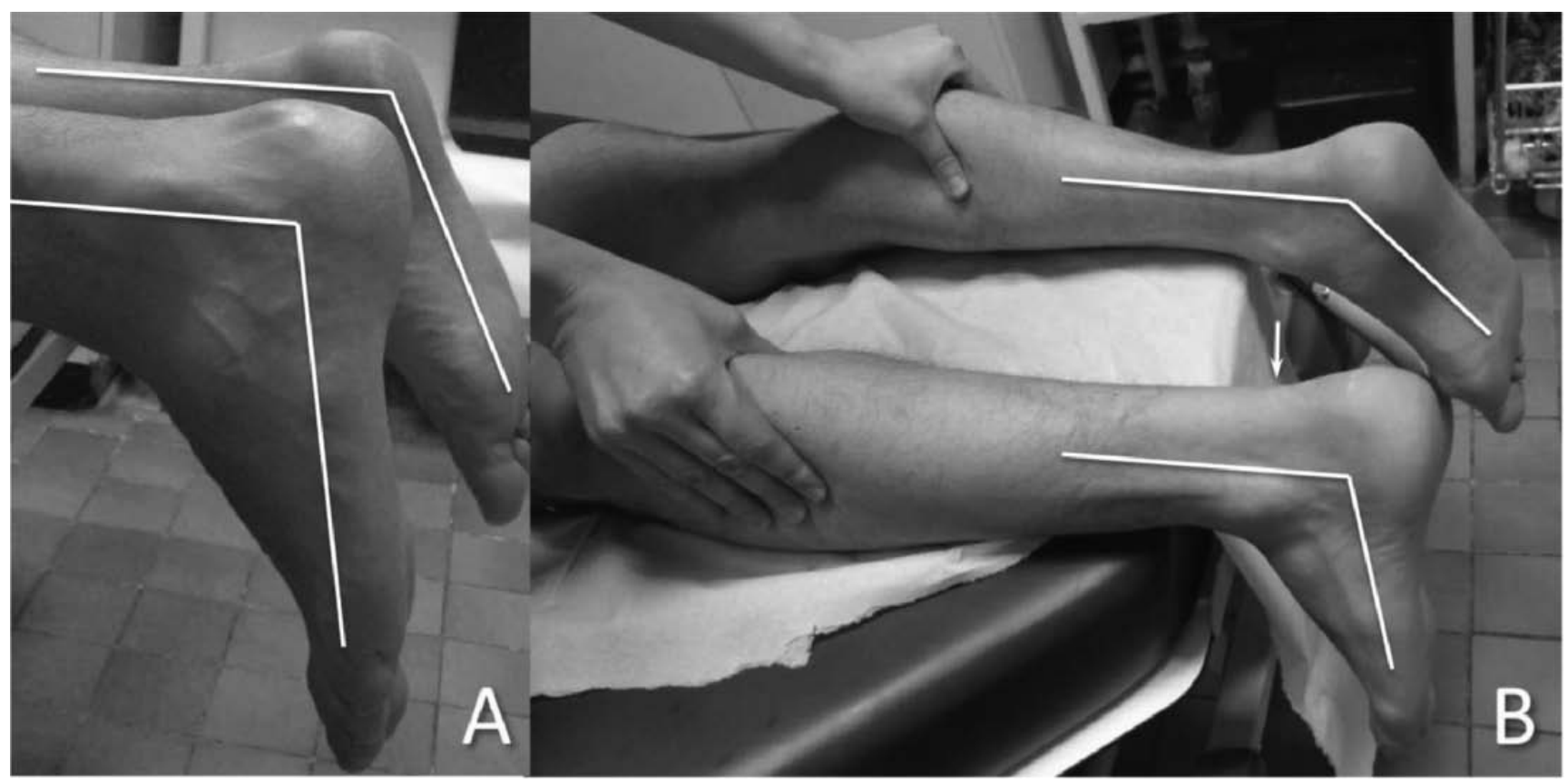

Fig. 1 Rupture du tendon achilléen du pied gauche : perte de l'équin physiologie du pied gauche (A), asymétrie du relief des tendons (flèche) et signe de Thompson positif : la pression du mollet gauche n'entraîne pas de flexion plantaire du pied (B)

Un patient de 30 ans consulte aux urgences pour un traumatisme de la cheville gauche en flexion plantaire contrariée. Les critères d'Ottawa sont négatifs. La flexion plantaire active en charge est impossible (la flexion plantaire active en décubitus reste possible grâce à l'action des fléchisseurs des orteils et du tibial postérieur). Il existe un œdème rétromalléolaire et une asymétrie du relief des tendons. La palpa- tion révèle un hiatus au niveau du site lésionnel et une douleur du tendon calcanéen irradiant vers le mollet. En décubitus ventral, on objective une perte de l'équin physiologique du pied (Fig. 1A) ainsi qu'un signe de Thompson positif : la pression du mollet n'entraîne pas de flexion plantaire du pied (Fig. 1B). Il s'agit d'une rupture complète du tendon calcanéen.

\section{Giron $(\bowtie) \cdot$ O. Peyrony $\cdot$ J.-P. Fontaine \\ Université Paris VII, UFR de médecine, Site Villemin, \\ 10, avenue de Verdun, F-75010 Paris, France \\ e-mail : camille.giron@hotmail.fr}

Service des urgences, hôpital Saint-Louis,

Assistance publique-hôpitaux de Paris,

1, avenue Claude-Vellefaux, F-75010 Paris, France 